This item was submitted to Loughborough's Research Repository by the author.

Items in Figshare are protected by copyright, with all rights reserved, unless otherwise indicated.

\title{
Instability tests for air-jet textured yarns
}

PLEASE CITE THE PUBLISHED VERSION

http://dx.doi.org/10.1177/004051758605600306

\section{PUBLISHER}

Sage (๑) Textile Research Institute)

\section{VERSION}

AM (Accepted Manuscript)

\section{PUBLISHER STATEMENT}

This work is made available according to the conditions of the Creative Commons Attribution-NonCommercialNoDerivatives 4.0 International (CC BY-NC-ND 4.0) licence. Full details of this licence are available at: https://creativecommons.org/licenses/by-nc-nd/4.0/

\section{LICENCE}

CC BY-NC-ND 4.0

\section{REPOSITORY RECORD}

Demir, Ali, Memis Acar, and Gordon R. Wray. 2019. "Instability Tests for Air-jet Textured Yarns". figshare. https://hdl.handle.net/2134/20000. 


\title{
Instability Tests for Air-Jet Textured Yarns
}

\author{
A. DEMIR, M. ACAR, AND G. R. WRAY \\ Loughborough University of Technology; Loughborough Leicestershire,, LE11 3TU, England
}

\begin{abstract}
The air-jet texturing process is briefly introduced and its advantages over other texturing processes are summarized. Characteristics of air-jet textured yams are stated with special reference to the stability of the yams. Test methods used in industry and research to determine the "stability" or "instability" of air-jet textured yams are critically reviewed. These methods involve different basic principles and therefore inevitably give different results. There is no consensus on a standard method. Effects of various test parameters, such as specimen length, test duration, and the alternatives of using a single yarn, a hank, or a skein as a test specimen are investigated. An improved test method is suggested as a standard instability test, and various existing methods are compared with it. Results of all the methods show similar trends for varying values of air pressure. Other yam characteristics such as linear density, breaking elongation, and tenacity are also determined, and their indications of yam quality are compared with the indications of instability tests. Stability test results alone provide misleading information regarding air-jet textured yam quality.
\end{abstract}

Warmth, handle, natural texture, and appearance are desirable properties of textile yarns. Flat, continuous synthetic filament yams do not possess such qualities, but more often they are stronger and much more uniform than the natural fiber yarns. When producing textile yams from synthetic filaments, it is ideal to combine the desired properties of both natural and synthetic fibers, but this is an impossible task to achieve, so the primary objective of all synthetic yarn conversion processes is to imitate the features of the natural fiber yams while maintaining the desirable properties of synthetic fibers.

One of the methods of achieving this is to cut the continuous filaments into staple fibers and then process them into yam form using conventional spinning methods, but this is a time consuming, costly process. Alternatively, continuous filaments can be converted into yarns by various texturing methods at lower costs, but often these inadequately simulate spun yams.

Texturing in general can be described as a technique by which closely packed parallel arrangements of continuous synthetic filaments are changed into more open, voluminous structures. Most of the texturing methods involve simple mechanical distortion during heat treatment of the thermoplastic yams. In contrast, the air-jet texturing process is a purely mechanical texturing method that uses a cold air stream to produce bulked yams of low extensibility; these more closely resemble spun natural fiber yams in their appearance and physical characteristics (see Figure 1). 


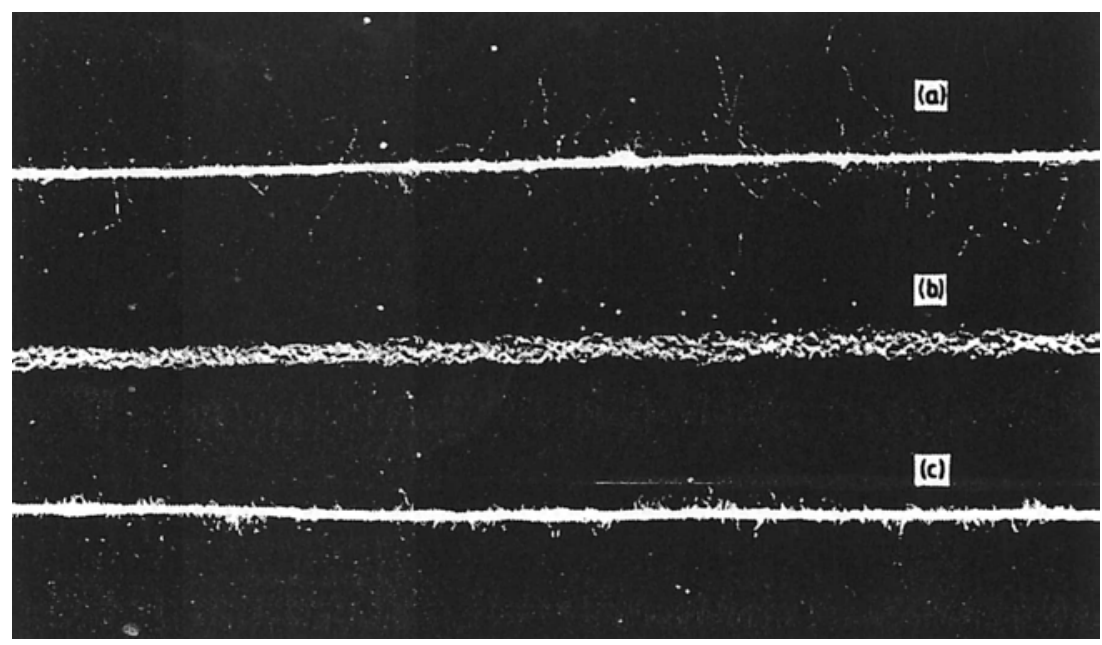

Figure 1. The visual comparison of (a) cotton yam, (b) false- twist textured yam, and (c) air-jet textured yam.

Yams textured by the methods based on heat setting during mechanical distortion have a common characteristic of high extensibility under quite low loads. This extreme extensibility arises from the very open structures that result in such "stretch" yams.

Yams produced by the air-jet technique (Figure 2) are totally different structures in that they much more closely simulate spun yam structures. Whereas the bulkiness of the stretch yams decreases with the degree of tension imposed on them, the form of air textured yams can be made to remain virtually unchanged at loads corresponding to those normally imposed in fabric production and during wear. This is due to the "locked-in" entangled loop structure attributed to air-jet textured yarns, as shown in Figure 2. Air-jet textured yarns again more closely resemble conventionally spun yarns in that the yarn surface is covered with fixed resilient loops, and these serve the same purpose as the protruding hairs in spun yarns by forming an insulating layer of entrapped stillair between neighboring garments.

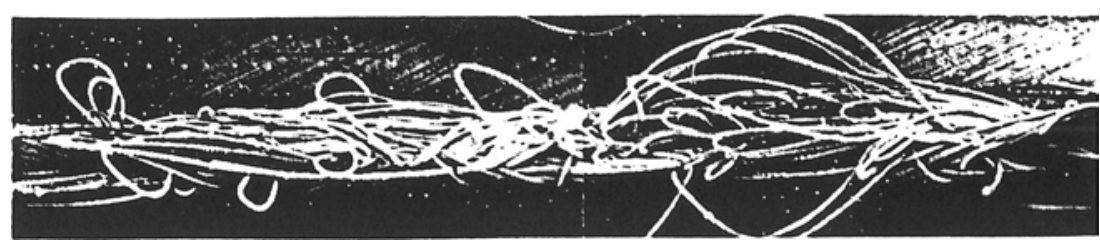

Figure 2. SEM photograph of an air-jet textured yarn.

The air-jet texturing process is by far the most versatile of all the yarn texturing methods in that it can "blend" filaments together during processing. This greater versatility offers the texturizer far greater scope than other types of textured yarns. Moreover, the feed yarns need not be restricted to the synthetic filament yarns with their good thermoplastic properties. Although polyester and polyamide multifilament types have so far been mainly used for the air-jet yarn products, other filament types such as polypropylene, glass, and viscose and acetate rayons are also being used for certain specialty products. 


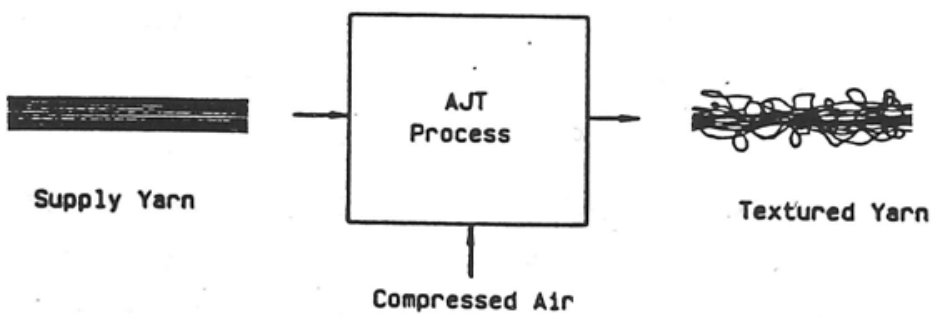

Figure 3. The block diagram of air-jet texturing.

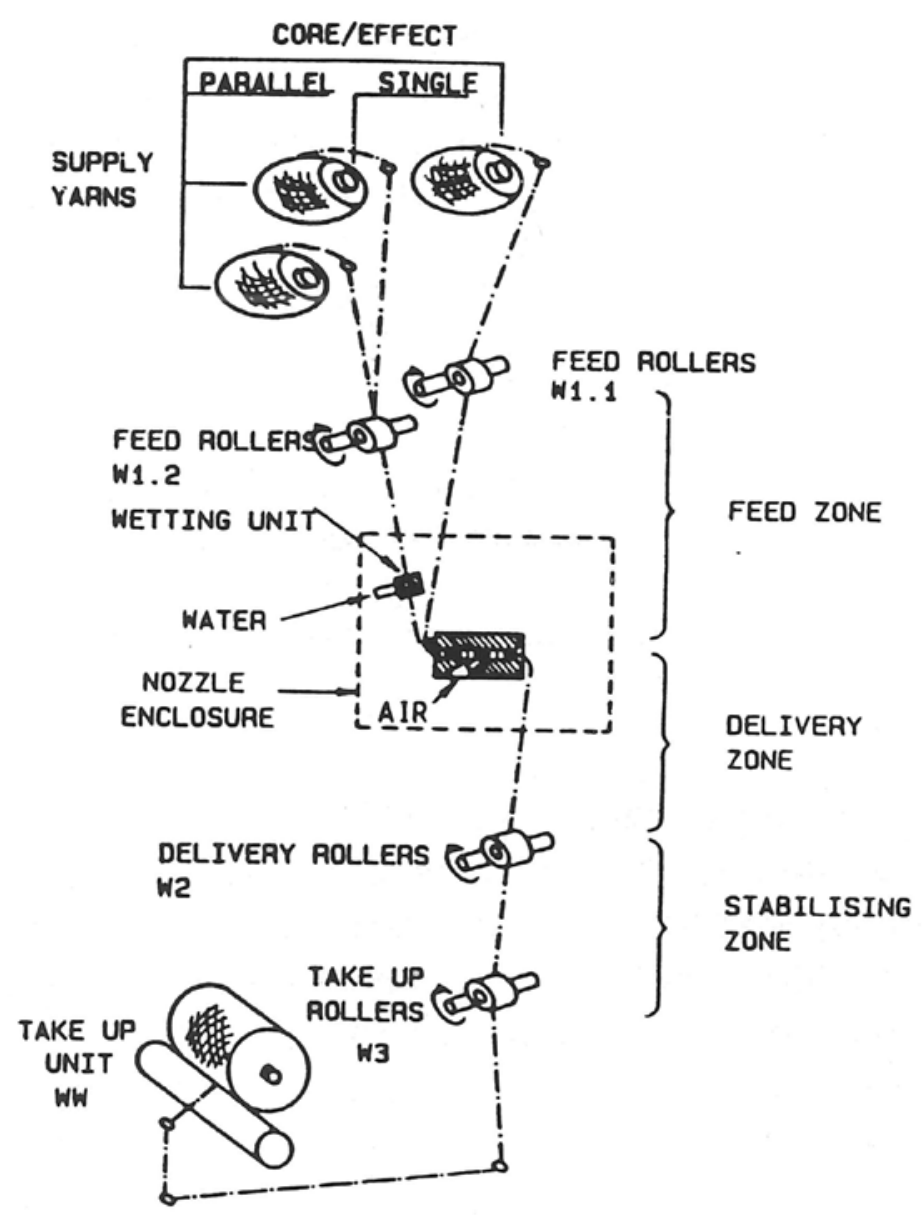

Figure 4. Schematic illustration of the principles of the air-jet texturing process.

\section{The Air-Jet Texturing Process}

Theair-jet texturing process converts flat, continuous synthetic yarns into entangled, convoluted, bulky, spun-like structured yarns (see Figure 3).

Figure 4 schematically illustrates the basic requirements of an air-jet texturing process. The process involves the "overfeed" principle where the multifilament supply yarn, as supplied "over-end" from a creel, is fed into the nozzle at a greater rate than it is taken away. To achieve this degree of overfeed, the yarn passes through the feed roller 
systems Wl.l and/or Wl.2 faster than it does through the delivery roller systems W2. The overfed filaments enter the nozzle and are blown out from the exit end; they are formed into textured yam under the turbulent effects of the cold air stream provided from a suitable compressed air supply.

The zone between the feed rollers and the nozzle is called the feed zone, and the zone between the nozzle and the delivery rollers, the delivery zone. The supply yam is normally wetted just before it is fed into the texturing nozzle by passing it through a water bath or a wetting unit that can either be separate or integrated in the nozzle assembly. Wet texturing apparently improves the quality of the yam produced. It is also believed that an impact element such as a baffle ball at the nozzle exit enhances the quality of the yarn (see Figure 5). Texturing nozzles are usually enclosed in a chamber, not only to reduce the noise created by the air-jet, but also to collect the used water and some of the spin finish that is washed away from the filaments during the process.

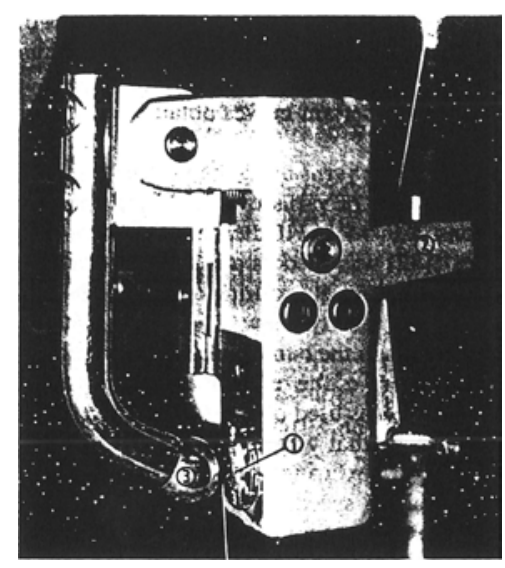

Figure 5. The photograph of HemaJet nozzle housing (I) texturing nozzle, (2) integrated wetting unit, (3) baffle ball.

Research directed towards the understanding of the air-jet texturing process can be cited as far back as 1960s, but it has recently continued at an increased pace. A brief review of previous research and the history of industrial nozzle development can be found in publications by Wilson [21], Acar et al. [2], Wray and Acar [24], and Acar [1]. The research work by Wray [22, 23], Wray and Entwistle [25, 26], Sivakumar [20], Sen [19], Kollu [15], Bock and Luenenschloss [7-9], Bock [6], Artunc et al. [5], Artun9 [4], Piller [16, 17], Piller and Lesykova [ 1 8], Acar et al. [3], and Fisher and Wilson [1 2] has contributed to the understanding of the process.

The work we report in this paper is part of continuing research using a Heberlein HemaJet T 100 [14] and a single-head texturing machine purpose-designed and built at Loughborough University of Technology to give maximum flexibility to the processing parameters.

\section{STABILITY OF AIR-JET TEXTURED YARNS}

A close examination of a typical sample of air-jet textured yarns reveals that some of the loops that characterize such yams can be pulled out by applying tension. This is illustrated in Figures 6a through e by the photographs of a typical portion of air-jet textured yarn under progressively applied leads of 50, WO, 200, 300, and 400 gf, respectively. Figures 7a through 7e show the same yam portion when the load is released in the reverse order. It illustrates that 
the loops do not recover their original shapes and positions, i.e., some loops are at least partially pulled out, and thus it is likely that the yarn will be permanently extended. If the tension is further increased so as to break the yam, examination of the broken yam reveals that some of the loops are still intact on the yarn as shown in Figure 8. The number of loops remaining intact depends on the stability of the loops. This is determined not only by the supply yam properties, such as material, linear density per filament, number of filaments, and shape of the filament cross section, but also by the process parameters such as kind of nozzle, air pressure, texturing speed, overfeed, and whether wet or dry processing is involved.
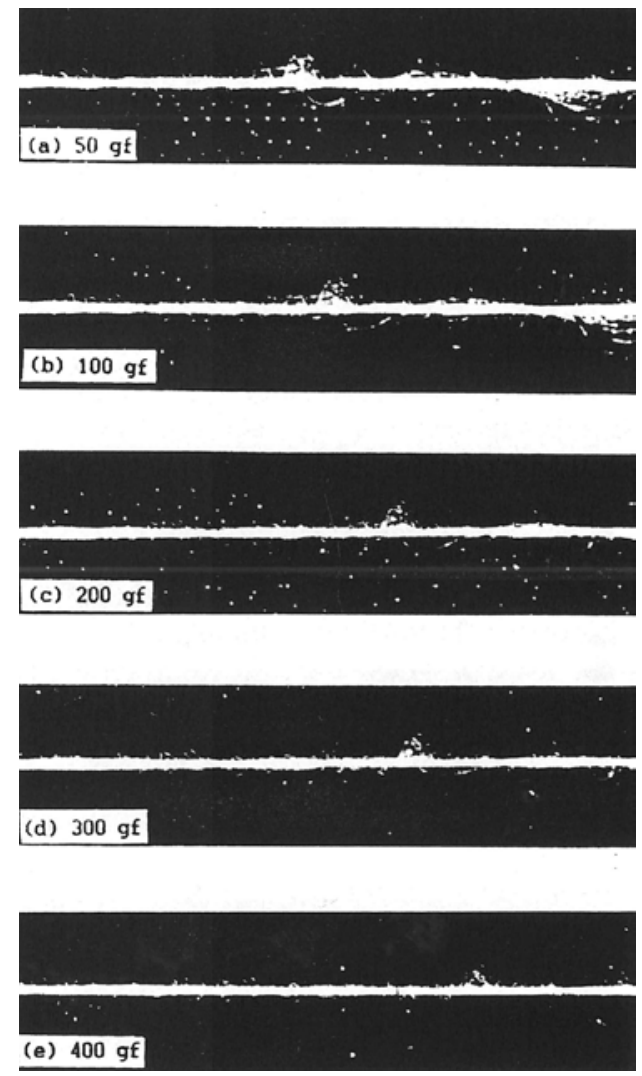

Figure 6. Air-jet textured yarns under increasing tension.
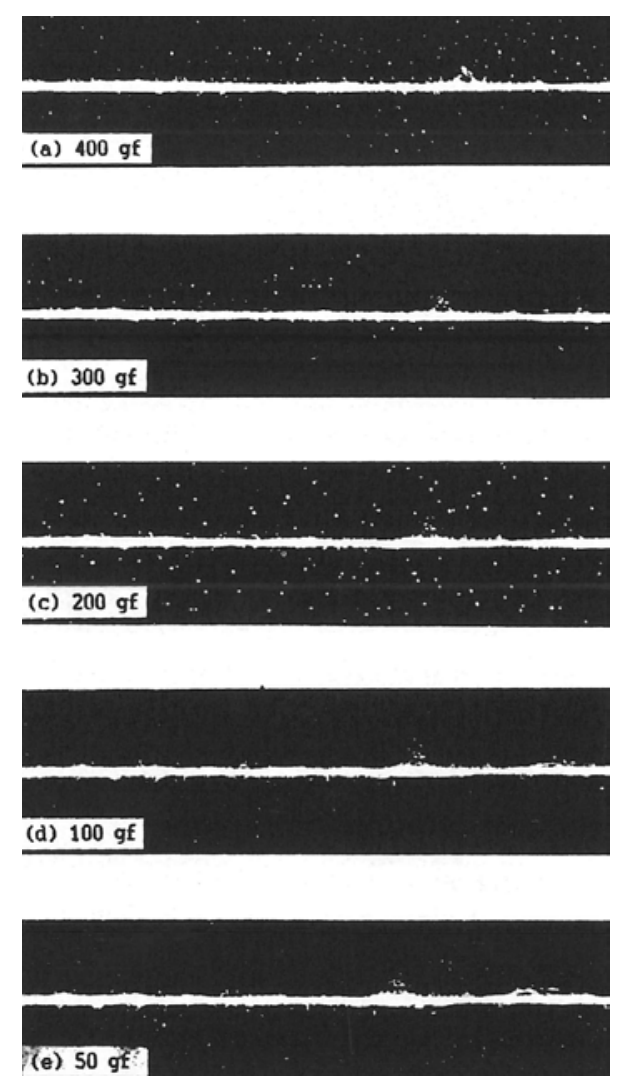

Figure 7. Air-jet textured yams under decreasing tension.

Loops that pull out easily under working tensions would be a disadvantage in fabric forming processes, since the bulk of the yarn would be reduced and the possibility of fabric irregularity increased. Therefore, a quality control test is required to determine the stability of the yarn. Unfortunately there is no widely accepted standard method.

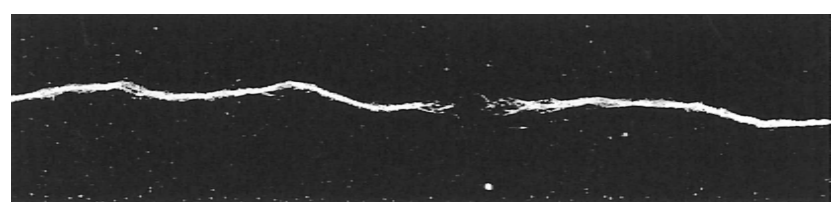

Figure 8. A broken air-jet textured yarn, illustrating that not all the loops have been pulled out. 


\section{Experimental}

\section{STABILITY TESTS}

Two test methods have apparently been used in industry. They both depend on hanging weights, either at one end of a single yarn or a hank of yarn, but they have basic differences in their method of calculation as a consequence of the different stability concepts involved. Methods based on other techniques for measuring the yarn stability have also been described and used in various research works, these being mainly based on load-elongation curves obtained by tensile tests or on stress-strain curves obtained by a strainometer.

In order to test yarns using the various methods, we textured a series of yarns over a range of processing conditions. A two-fold $110 \mathrm{dtex} / \mathrm{f} 66$ polyester yarn (i.e.. $220 \mathrm{dtex} / \mathrm{fl} 32$ ) was used as a supply yarn, this being very suitable for air-jet texturing because the individual filament linear density is low (1.67 dtex) and the number of filaments in the bundle ishigh. Heberlein's T100 texturing jet, one of the recent nozzles for yarns in the apparel range, was used on a versatile single head texturing machine that was purpose-built in Loughborough for air-jet texturing process research [1]; $400 \mathrm{~m} /$ minute texturing speed, $20 \%$ overfeed, 7 bar (gauge) air pressure with water applied at a rate of 1 liter/hour were taken as standard texturing conditions. When any one of-these process parameters was altered, all the other parameters were kept constant at the standard conditions. Tests were made of other yarn properties, namely linear density, tenacity, and breaking elongation, so that they could be related to the measures of stability.

\section{WEIGHT HANGING METHODS}

\section{Du Pont Method}

The Du Pont Company, one of the first in the field of air-jet texturing, defined a stability test for Taslan yarns [11]. Its purpose is to determine the permanent increase in length of a textured yarn after applying a load and removing it after a certain time has elapsed, this being an indication of the stability of the texturing effect. For this purpose, a simple stability tester is de- scribed comprising a vertical board with a toggle clamp at the top on which to hang the textured yarn. At a distance of $100 \mathrm{~cm}$ below is a marking notch and beneath this is a centimeter scale. Provision is made for hanging weights on the specimen yarn by means of a weight hanger.

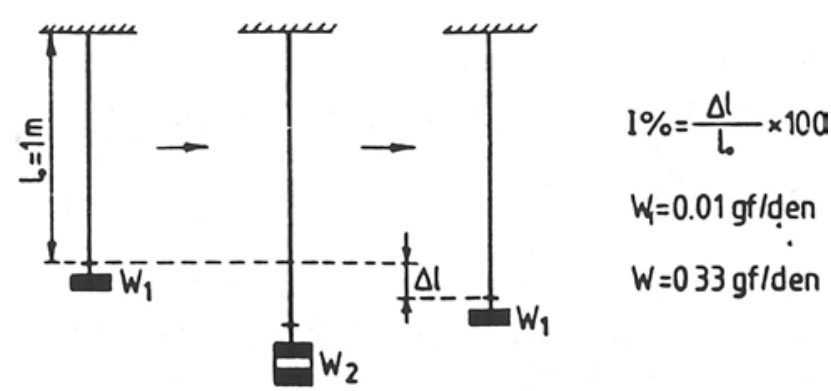

Figure 9. Du Pont's stability test method.

The procedure is illustrated in Figure 9 and can be described as follows: A weight of approximately $0.0 \mathrm{lgf} /$ denier W1 is hung at the end of the yarn, and this weight is left on the specimen throughout the test. A $100 \mathrm{~cm}$ section on the thus tensioned specimen is marked. The specimen is then subjected to a further load of $0.33 \mathrm{gf} / \mathrm{denier}$ W2 (based on the textured yarn linear density) for 30 seconds. Using the $100 \mathrm{~cm}$ mark as datum, the permanent 
elongation in the length of the specimen is measured 30 seconds after the load W2 has been removed. This percentage elongation is taken as the direct reading of the stability. Du Pont suggests that a satisfactory textured yarn must have a stability of less than $5 \%$ [10].

As can be seen from the test procedure, a $100 \mathrm{~cm}$ long single yarn specimen is used to measure the permanent elongation in the yarn. The applied load W2 is 0.33 gf/denier and it is applied for 30 seconds. Al- though Du Pont does not explain why a load of $0.33 \mathrm{gf} / \mathrm{denier}$ is applied and why it is applied for 30 seconds, it appears reasonable to use a $100 \mathrm{~cm}$ specimen length to facilitate a direct percentage reading.

\section{Heberlein Methods}

In another weight hanging test method (13], suggested by the Heberlein Company of Switzerland, a hank of textured yarn is used instead of a single yarn specimen. The yarn is wrapped on a reel of a $100 \mathrm{~cm}$ circumference in order to form a small hank of approximately 2500 dtex, the number of wraps being 2500 (dtex), the number of wraps being

No. od wraps $=2500$ dtex $/ 2$ x supply yarn linear density (dtex)

As indicated in Figure 10, the hank is first tensioned for 60 seconds with approximately 25 $\mathrm{cN}$ load (corresponding to $0.01 \mathrm{cN} / \mathrm{dtex}$ ), based on the linear density of the untextured yarn, and length $a$ is measured. A load of $1250 \mathrm{cN}$ (corresponding to $0.5 \mathrm{cN} / \mathrm{dtex}$ ) is then substituted for this load and applied for 60 seconds and the length $b$ is recorded. 60 seconds after removing this load, the $25 \mathrm{cN}$ load is reapplied to the hank and, after a further 60 seconds, the length $c$ is measured.Two values are then calculated for instability:

$$
\begin{aligned}
& \text { Instability I }(\%)=[(b-a) / a] \times 100 \\
& \text { Instability II }(\%)=[(c-a) / a] \times 100
\end{aligned}
$$
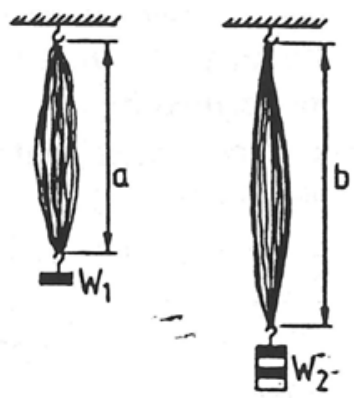

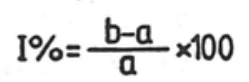

II $\%=\frac{c-a}{a} \times 100$

$W_{1}=0.01 \mathrm{cN} / \mathrm{dtex}$

$W_{2}=0.5 \mathrm{cN} /$ dtex

Figure 10. Heberlein'sinstability test method.

Instability I measures the percentage elongation of the yarn while under a certain applied load, which is a different concept than Du Pont's measurement of permanent elongation after the load has been removed. It appears that Heberlein was somewhat unsure about the concept of instability and therefore suggested a second way to measure it; hence Instability II measures the permanent elongation in the yarn after the applied load has been removed, similar to the Du Pont method.

In contrast to the Du Pont method, the term instabilityis used by Heberlein, instead of stability following Wray's earlier suggestion. Wray-(23] had stated in 1969 that "The use of the word 'stability' for the values obtained by the Du Pont test is unfortunate since the lower the percentage value the more stable is the yarn. A more correct term for this measurement would have been 'instability'." [reference 23, p.117]

The term instability will therefore also be used throughout the rest of this paper. 


\section{OTHER INSTABILITY METHODS}

\section{Wray's Methods}

In 1965, during the early days of air-jet texturing when pretwisted yarns were used as raw material, Wray [23] observed that the textured yarn untwisted under the applied loads; he therefore claimed that the value of instability measured by any method that did not prevent untwisting included additional elongation due to removal of twist. Hence he devised an alternative method in which he made use of the Instron constant rate-of-elongation tensile tester, which did not suffer from losing yarn twist during testing. From the load elongation curve, as illustrated in Figure 11, he defined the instability of the yarn as follows:

$$
\text { Instability }(\%)=e_{t}-e_{p}
$$

where $e_{p}$ and $e_{t}$ are the percentage elongation of the supply and textured yarns, respectively, at a constant load of $W=0.33 \mathrm{gf} /$ denier (see Figure 11), this corresponding to the load used in the Du Pont tests.

This method of instability measurement was an attempt to eliminate the effect of the elastic deformation of straight, load carrying filaments of the textured yarn. Wray [23] claimed that the percentage permanent elongation in the textured yarn was obtained by this method, by subtracting the percentage elongation of the supply yarn $\left(e_{p}\right)$ from the percentage elongation of textured yarn $\left(e_{t}\right)$. The implication was that the elongation of textured yarn under an applied load also included the elastic deformation of the constituent filaments, i.e., elongations of the individual filaments also contributed to the instability of the textured yarn.

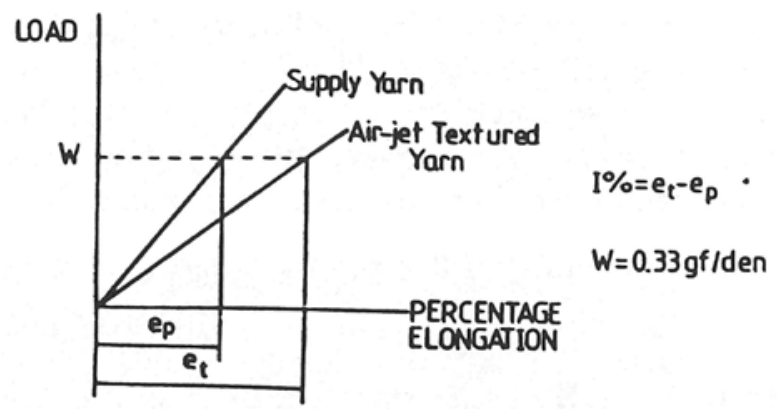

Figure 11. Wray's instability concept.

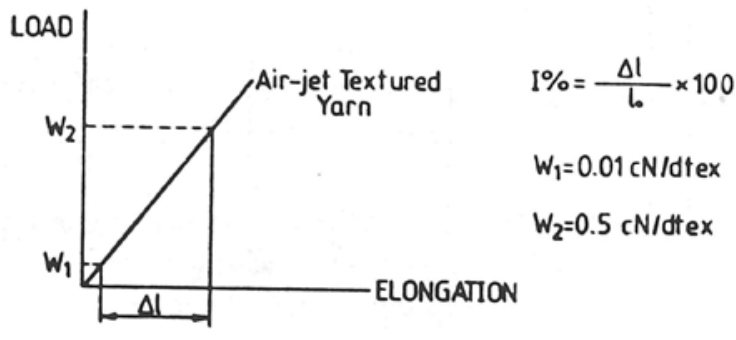

Figure 12. Acar's instability concept.

Although it is true that the load bearing filaments will elongate under the applied loads (whereas loop forming filaments will not), it is not known what amount of elongation is caused by the pulling out of loops and what amount is caused by the elastic deformation of the individual filaments; therefore, it is debatable whether the measurements obtained by this method reflect the permanent elongation of the textured yarn.

Wray [23] also devised a quicker method of measuring yarn instability based on principles similar to the Instron tensile tester method. This technique incorporated the use of a strainometer, which imposed a 5\% constant strain on the yarn as it passed continuously over rollers. A third roller between these two rollers acted as a sensor to measure the tensions in the yarn, which enabled a calculation of the yarn instability to be made. Unfortunately, this method suffers from the same shortcomings described above. 
A recent suggestion for instability measurements of air-jet textured yams was made by Acar (2), this being also based on the load-elongation curves from a tensile testing machine of the lnstron type. He measured the percentage elongation corresponding to loads of $0.01 \mathrm{cN} / \mathrm{dtex}$ and 0.5 cN/dtex, corresponding to the loads used in the Heberlein tests, as a measure of the yarn instability (see Figure 12). Hence,

$$
\text { Instability }(\%)=\Delta \mathrm{l} / \text { specimen length }
$$

Acar's method suggests that the elongation of textured yarn under applied loads should be taken as the mea- sure of yarn instability, rather than the difference of elongations of the textured and supply yarns, as suggested by Wray, because the contribution of the ex- tension of load-bearing parallel filaments of the textured yam to the overall elongation is difficult to account for.

\section{Results and Discussion}

\section{TWOCONTRASTING YARN INSTABILITY CONCEPTS}

As seen in the previous section, the instability methods used in industry and by research workers vary considerably, not only as regards detail but also the basic agreement as to what actually needs to be measured. Nevertheless, we suggested that they can be grouped into two contrasting categories from the viewpoint of the concept of instability: (a) The concept of instability as a measure of the tendency of the textured yarn to elongate under maintained applied loads, thereby corresponding to the loads applied during later processes such as weaving, knitting, etc. Therefore, no attempt is made to account for the separate contributions of loop removal and elastic (recoverable) deformation to yarn elongation, because the percentage elongation under a maintained applied load is taken as a measure of instability, e.g., Heberlein instability method I and Acar's; method which uses an lnstron tensile testing machine..(b) The concept of instability as a measure of the lack of permanence of loops formed by the texturing process whereby the elastic (recoverable) deformation of the yam under the applied load does not contribute to the yarn instability because the load is removed to allow the yarn to recover from such elongations before measurement occurs. Therefore the percentage permanent elongation is taken as the measure of instability, e.g., Du Pont method, and the Heberlein instability II method.

It is clear that no consensus exists regarding the basis for a standard method for instability measurement, and inevitably the results reported by various research workers do not agree with each other. Therefore there is a need for a standard instability test for air-jet textured yarns. In the following sections, the known instability methods will be critically analyzed and, in or- der to initiate discussion of the subject, a method based on one of the above two contrasting concepts will be suggested as a standard method.

\section{SIMULATION OF WEIGHT HANGING METHODS USING A TENSILE TESTER}

The procedure used in weight hanging methods is rather tedious and the load is applied for rather arbitrarily chosen periods. For instance, Du Pont suggests that the measurement of permanent elongation should be taken after a 30 second application of $0.33 \mathrm{gf} / \mathrm{denier}$ weight and a 30 second relaxation following the removal of this load, where a weight of 0.01 gf/denier is constantly applied throughout the test. On the other hand, Heberlein suggests a 60 second application of a $0.5 \mathrm{cN} /$ dtex weight and a 60 second relaxation without any weight, followed by a 60 second application of a $0.01 \mathrm{cN} / \mathrm{dtex}$ load before reading the permanent elongation. 
Test results for varying air pressure are shown in Figure 13 for the Du Pont and Heberlein instability II methods, both of which measure the permanent elongations after the applied loads have been removed. Both tests give similar results, but the accuracy of the test results is rather low, because the elongation cannot be read as accurately as with an Instron tensile tester, and human errors are inevitable during the test.

Alternatively the weight hanging methods can easily be simulated by using a tensile testing machine of the lnstron type. The required load can be applied to the specimen yam, and a certain time can be allowed to elapse before the load is released. Hence the permanent extension of the yam after the load is removed can be calculated more accurately from the load-elongation curves so as to simulate instability the concept mentioned earlier. Since, as will be shown in the next section, relaxing the yam under an applied load for a certain period has an insignificant contribution to the elongation of the yam, the tensile testing machine can be set to extend the yarn until it reaches the required load, the action being immediately reversed when this load is reached so that the conditions revert to zero loading. Hence the permanent elongation of the yam can be measured as illustrated in Figure 14, which was obtained from an Instron tensile tester. Re5ults of such a test using the loads specified in the Heberlein tests are also plotted in Figure 13, which demonstrates reasonable agreement with the test results of the Du Pont and Heberlein II methods. The advantage of the simulation using the tensile testing machine is that it is accurate, faster, and relatively easier to perform than these weight-hanging methods.

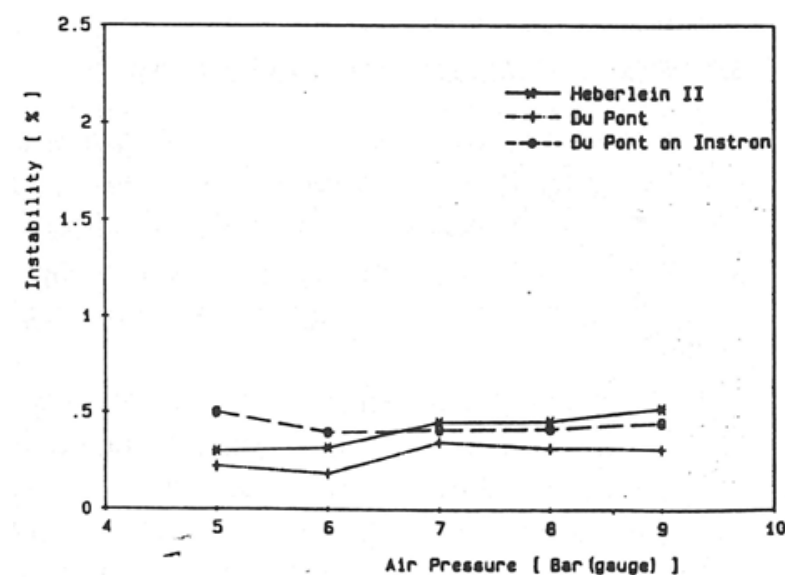

Figure 13. Comparison of instability test methods based on permanent elongation.

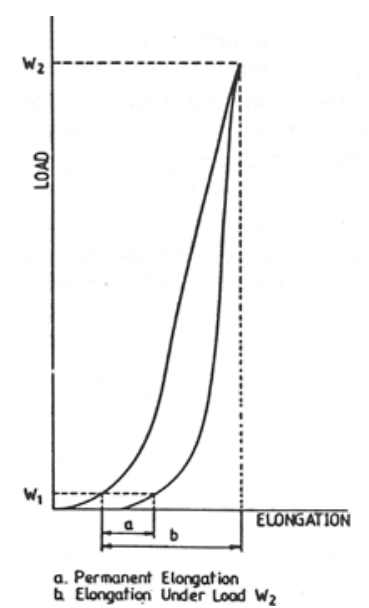

Figure 14. Simulation of a weighthanging instability test method using a tensile testing machine.

\section{EFFECTS OF TEST LOAD AND DURATION OF APPLICATION}

The different loads used for the Heberlein and Du Pont stability tests cannot both be representative of the applied tensions during further processing into fabrics. Therefore, a representative standard load should be decided, based on practical fabric forming process conditions, and only this load should be used in the instability tests. This will require further investigation, but we use the loads suggested by Heberlein in the tests reported in this paper.

Is the duration of the applied load important? To answer this question, we designed an experiment using an Instron tensile tester that can provide very accurate readings. A constant test load of $110 \mathrm{cN}$, equivalent to loads used in Heberlein instability tests (i.e., $0.5 \mathrm{cN} / \mathrm{dtex}$ ), was applied to a specimen of the "standard" yarn (see section on stability tests) for 15 minutes. 
The test procedure was as follows: the Instron ma- chine was set to $112 \mathrm{gf}$ and the elongation of the yarn started. When this load was reached, the elongation of the yarn was stopped automatically. As the time elapsed, the load applied to the yarn decreased gradually below the preset value of $112 \mathrm{gf}$ due to the relaxation in the yarn. Then the machine automatically restarted the elongation process, which was again stopped automatically when the load reached the preset value of 112 gf. This cycle repeated itself several times within the 15 minute test period.

Figure 15 is a reproduction of the chart recording from such a test, illustrating that the application of a constantly maintained load for a certain period can have a slight effect on the extension of the yarn, especially during the early stages of the load application period. Nevertheless, the overall effect within the 15 minute test duration was insignificant, as illustrated in Figure 16. The initial elongation of the yarn under the applied test load was $1.868 \%$. The additional effects of applying a constantly maintained load for 30 and 60 second durations were only to increase the elongations to 1.881 and $1.885 \%$, respectively, and indeed total elongation for a 15 minute application of this load was only $1.897 \%$. We can conclude that the constantly maintained application of the test load has a negligible effect on the elongation of the yam and hence on the instability test results. Consequently, the application of constant loads for any specified time periods can be eliminated.

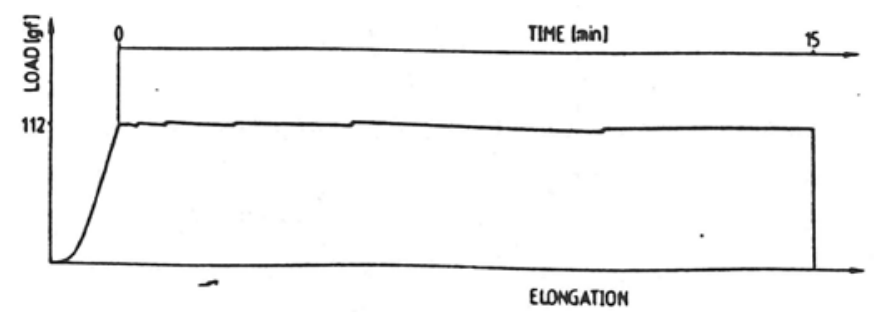

Figure 15. Load-elongation diagram for an air-jet textured yarn with a constant load applied over 15 minutes.
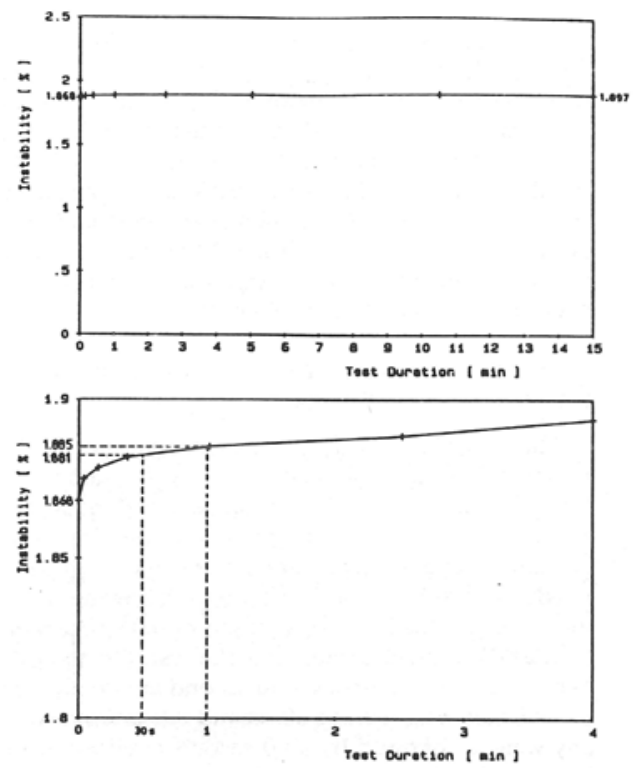

Figure 16. Effect of test duration on yarn instability (top). Magnification of the top figure to show the effect of the first 4 minutes of load application (bottom). 


\section{EFFECTS OFSPECIMEN TYPE AND LENGTH}

Heberlein suggests the use of a hank of yarn in the tests, while Du Pont uses a $100 \mathrm{~cm}$ long single yarn. Does using the hank instead of a single yarn affect the test results? Does the specimen length have a significant effect? Some answers to these questions will be sought in this section.

First, we examine the effect of using a hank and a bundle of yarn instead of a single yarn. Using the Instron machine and Acar's test method, we performed the following tests: (a) with a single end of yarn fixed in the pneumatic jaws (Acar method), test results are shown in Table I. (b) With a hank of yarn hung over hooks fixed in the pneumatic jaws. Since the hank opened out under the applied load, it was not possible to conduct the test when the two ends of the yarn in the hank were left free. Therefore, although this adverse effect is not made clear by Heberlein, two ends of the yarn had to be tied to make a closed loop hank for the tests to be undertaken and thus to achieve an equal distribution of the load to each constituent loop in the hank. The test results (Table I) show that this closed loop hank method (Heberlein I on the Instron) gives a slightly higher instability than the results obtained using a single yarn specimen (method a). (c) With a bundle of yarns fixed in the pneumatic jaws. This creates a positive grip of each yarn within the bundle. As shown in Table I this test showed slightly higher instability than the other two methods, which can be attributed to the non-uniform distribution of the load to every yarn in the bundle. We therefore concluded that this is not a suitable method for yarn instability tests.

Table I. Comparison of instability test results.*

\begin{tabular}{lc}
\hline Du Pont & 0.345 \\
Du Pont on Instron & 0.290 \\
Heberlein I & 2.134 \\
Heberlein I on Instron & 2.018 \\
Heberlein II & 0.450 \\
Heberlein II on Instron & 0.410 \\
Hank with pneumatic clamps & 2.151 \\
Wray & 1.458 \\
Acar & 1.868 \\
*Texturing conditions deployed to produce the \\
standard yarn used in these tests were 7 bar (gauge) \\
air pressure, 20\% overfeed, 400 m/ minute texturing \\
speed, and I liter/hour water consumption.
\end{tabular}

It can be argued that a single yarn specimen, such as method a, is the most suitable basis for yarn instability tests because a single yarn is easier to handle and the question of a nonuniformly distributed load through the bundle does not arise. The only alternative to this could be a hank of yam with a closed loop (ends tied) hung on low friction hooks as in method b, and it might be argued that the longer specimen length might give a better overall representation of the yarn characteristics. But does the longer specimen length provided by a hank result in a better representation of the yarn characteristics? To answer this question we examined the effect of specimen length using a single yarn of various specimen lengths, 
and Figure.17 shows that the specimen length has an insignificant effect on the test results. We can therefore conclude that a single yarn should be used in the instability tests for its convenience in handling, the specimen length being chosen to suit the apparatus used and the testing conditions. Consequently, in the tests reported in this paper, we used a single end yarn with a $30 \mathrm{~cm}$ specimen length.

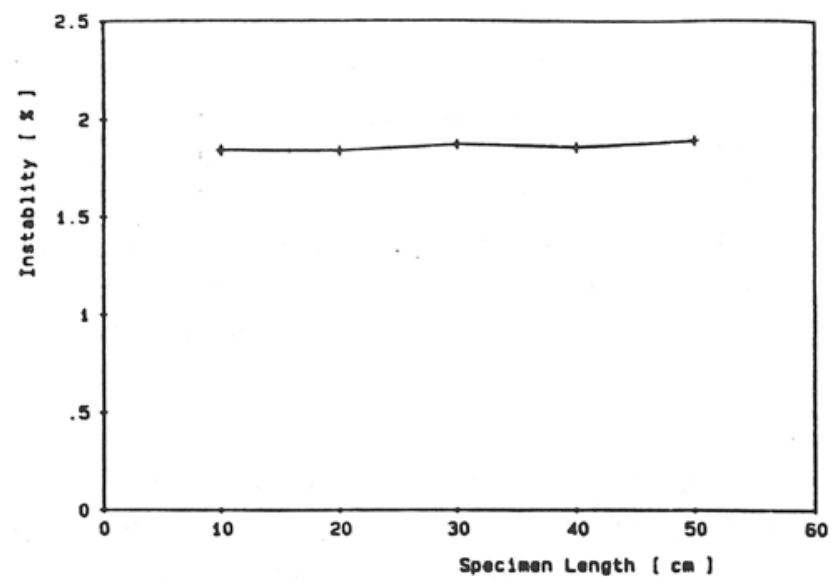

Figure 17. Effect of varying specimen length on the instability.

\section{Conclusions}

A consensus should be reached regarding the yarn stability concept. While some industrialists and re- searchers have assumed yarn instability to be a measure of the elongation of the air-jet textured yarn under an applied load, others have taken it to be a measure of the permanent elongation after such an applied load has been removed. Since, on the one hand, air-jet textured yarns are not stretch yarns and, on the other, they are under maintained tensions during most of the further fabric forming processes, i.e., while undergoing weaving or knitting, it would be more reasonable to take the elongation of the yarn under a maintained tension as a measure of yarn instability. Therefore the first concept more closely simulates real conditions.

Whichever concept is finally accepted as a basis for a standard test method of yarn instability, the tensile testing machines can be used for improved instability tests. As we discussed earlier an instrument such as the Instron machine gives more accurate readings of the yarn elongation, even under very small loads, than the crude weight hanging methods described earlier, and it is therefore more reliable than these.

A single yarn specimen is much easier to handle, and so it is more practical in use than a yarn hank or bundle. The specimen length has no significant effect on the tests, and hence any convenient length of yarn can be used.

The effect of the duration of the load application on the test results is not significant, and therefore applying- loads for relatively long periods is unnecessary. The amount of load that should be applied to the yam during the tests is far from general agreement, but it should be representative of the tensions imparted during further processing stages such as weaving, knitting, etc. 


\section{A RECOMMENDED TEST METHOD}

In the light of our work and the conclusions we derive from it , we recommend the following basis for an improved test method: (a) a tensile tester of Instron type should be used to measure the yarn elongation, (b)single yam specimens are adequate,(c)the specimen length should be sufficiently small to permit easy handling (a $30 \mathrm{~cm}$ length is convenient for most machines and is therefore recommended), (d) the elongation under this test load should be taken as a measure of the instability rather than the permanent elongation measured after the load is removed, because it represents the actual case that loads are constantly applied during other textile processes.

The procedure for this improved test would read as follows: (a) Prepare the tensile testing machine for the test. Recommended test conditions are as follows: distance between pneumatic jaws (i.e., specimen length) $30 \mathrm{~cm}$; cross-head speed, $2 \mathrm{~cm} /$ minute; chart-speed, $10 \mathrm{~cm} /$ minute. (b) Take approximately $50 \mathrm{~cm}$ length of textured yam from a representative package. Use care not to damage the yam during removal from the package. (c) Clamp both ends of the yam in the pneumaticjaws. Use care not to over-tension the specimen during clamping. (d) Operate the machine and record the elongation up to a value slightly greater than the load corresponding to $0.5 \mathrm{cN} / \mathrm{dtex}$, based on the untextured yam linear density. (e) From the recorded load-elongation chart, calculate the percentage elongation between the loads $0.0 \mathrm{l} \mathrm{cN} / \mathrm{dtex}$ and $0.5 \mathrm{cN} / \mathrm{dtex}$. This percentage elongation gives the instability of the yam. This procedure should be repeated for a reasonable number of randomly selected specimens, preferably from different packages of yam and from different places of one package, to obtain reliable test results.

The test results using this specified method are shown in Figure 18, and they are compared with the results of all the other methods described previously. Although they each yield different results because of differences in the concepts and assumed parameters on which they are based, they all show the same basic trend, i.e., in- creased instability with increasing values of the air pressure used for texturing.

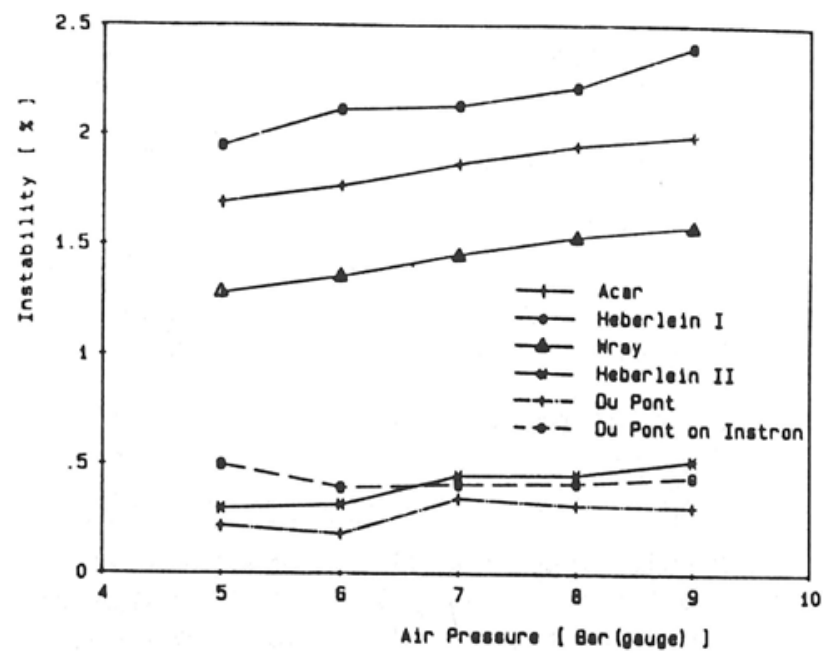

Figure 18. Comparison of different instability test methods for yams textured with varying air pressures.

\section{THE INADEQUACY OF INSTABILITY TESTS}

Instability tests alone are inadequate for judging the quality of air-jet textured yams. For example, yams textured at very low overfeeds, low air pressures, and high texturing speeds 
will exhibit a very small number of loops. Test results of such yams show low instability, and yet they would not be suitable for many end-uses. On the other hand, yams textured at high overfeeds, high air pressures, and low texturing speeds will exhibit increased numbers of loops and have desirable qualities for many end-uses, but they will be accompanied by higher instability values. If judging from the instability viewpoint alone, the first yam would appear to be preferable to the second yam, but obviously this would be misleading from the viewpoint of quality and consumer acceptability. Therefore the producer of air-jet yarns needs to measure other yarn properties, such as · percentage linear density increase, tenacity, percentage breaking elongation, and the number and frequency of loops as well as instability in order to obtain a total assessment of yam quality.

To illustrate this point, Figures 19a-d show the in- stability, percentage linear density increase, tenacity, and percentage breaking elongation of typical textured yams produced with varying working air pressures. Instability, as expected, shows an increase with increasing air pressure (Figure 19a), indicating a deterioration of yarn quality. This can be attributed to the higher number of loops at increased air pressure [23], which also increases the probability that many of these loops will be removed under the loads applied. An increased number of loops also causes the load to be shared by a reduced number of parallel filaments in the yam, which in turn contributes to increased yarn instability.
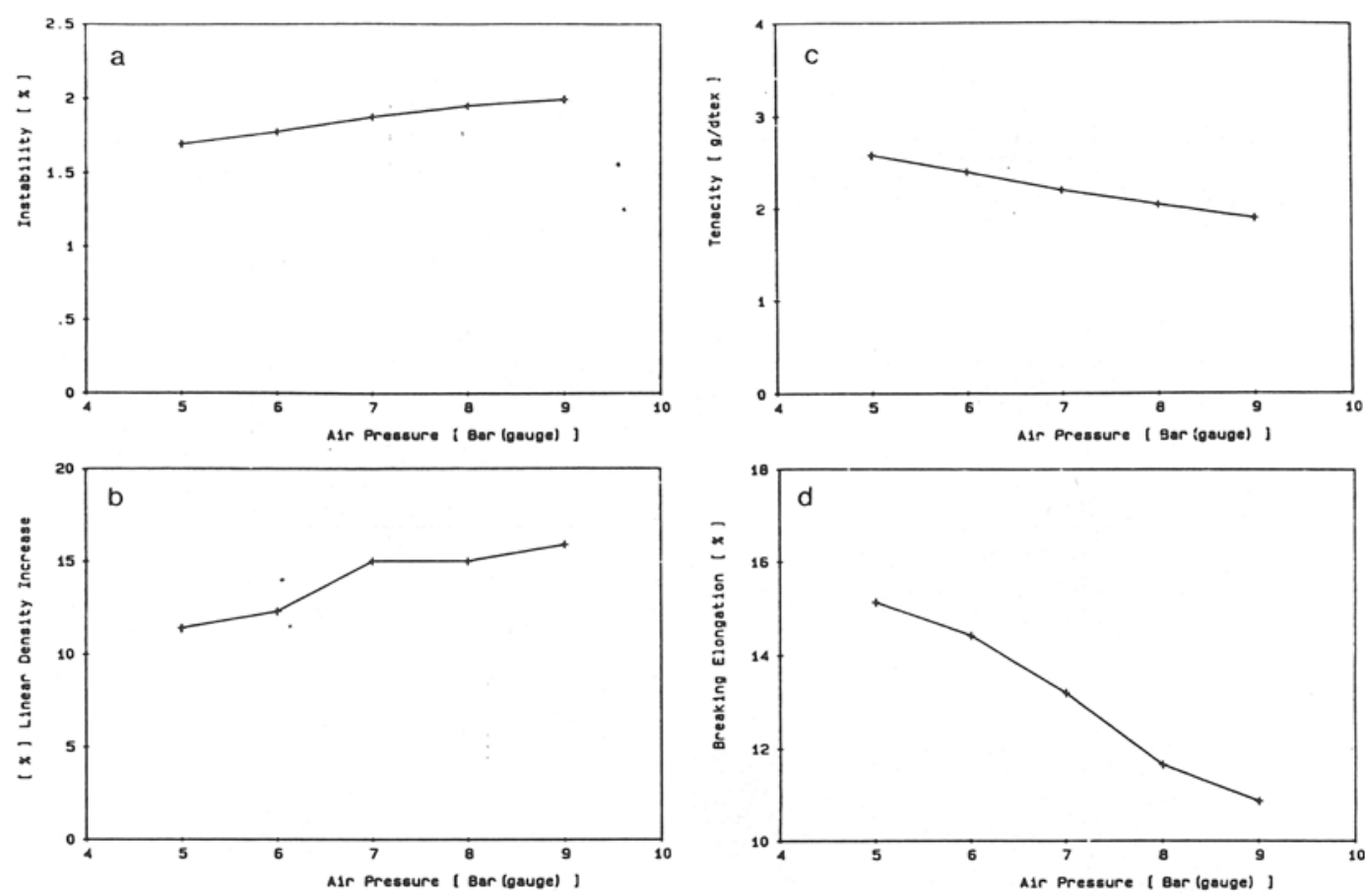

Figure 19. Properties of yams textured with varying air pressures: (a) instability, (b) percentage linear density increase, (c) tenacity, (d) percentage breaking elongation.

On the other hand, the yarn linear density increases with increasing working pressure (Figure 19b), thus indicating a better texturing effect due to a greater number of loops. The tenacity (Figure 19c) and breaking elongation (Figure 19d) both decrease with increasing working pressure, also indicating a better texturing effect and greater number of loops. The scanning electron microscope photographs shown in Figure 20 also show that the textured structure of these yarns improves with the greater air pressures. We can therefore conclude that, despite increasing yarn instability, the overall yarn properties are improved. 


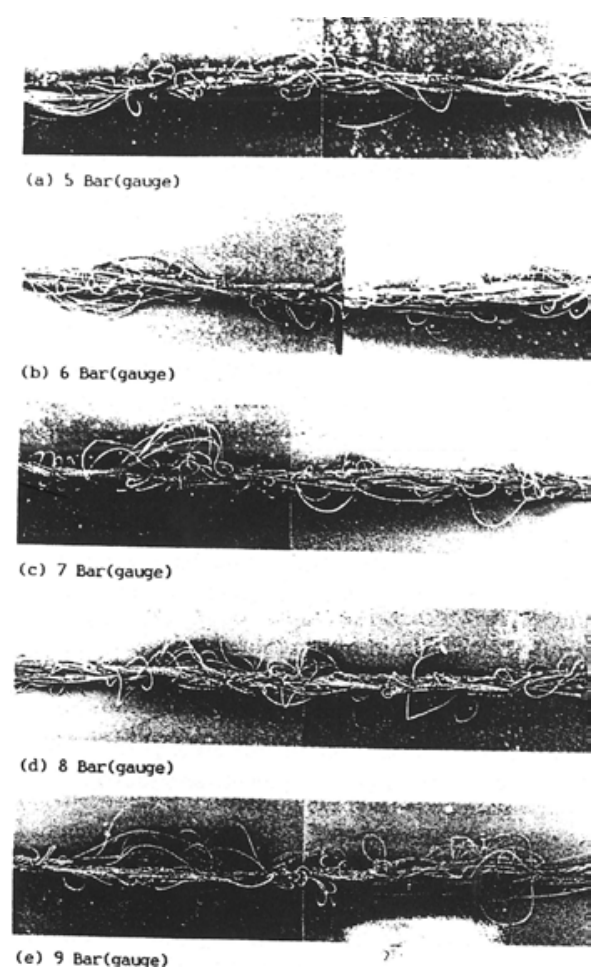

Figure 20. SEM photographs of yarns textured with different air pressures.

Consequently, we recommend that the structure and physical properties of the air-jet textured yarns should be analyzed before deciding on the suitability for particular end-uses. The instability tests should only be viewed as a precautionary assessment to warn the producer of any likely deterioration of the textured yarn structure during further processing. The amount of instability that can be permitted is therefore a matter of judgment for the producer so that all the desirable yam properties are transmitted to the final fabrics.

\section{ACKNOWLEDGMENTS}

We wish to acknowledge Mr. K. W. Tapley for the photographic work. A. Demir would like to thank the Turkish Government, Ministry of Education, for financial support.

\section{Literature Cited}

1. Acar, M., Analysis of the Air-jet Texturing Process and Development of Improved Nozzles, doctoral thesis, Loughborough University of Technology, England, 1984.

2. Acar, M., Alexander, A. J., Turton, R. K., and Wray, G. R., The Mechanism of the Air-jet Texturing Process, in "Texturing Today,"Shirley Institute Publications S.46, Manchester, 1983, pp. 207-230.

3. Acar, M., Turton, R. K., and Wray, G. R., An Analysis of the Air-jet Yarn Texturing Process, Parts I to VII (a series of papers to appear in J. Textile Inst.).

4. Artunc, H., The Air Texturing of Drawn and of High- speed Polyester Yarns, Chemiefasern/Textilind. 31/83, 289-297 and E29 (1981).

5. Artunc, H., Bocht, B., and Weinsdoerfer, H., "Air-jet Texturing Process with Integrated Drawing and Shrinking Zones, Chemiefasem/Textilind. 29/81, 857-861 and E 1 18-120 (1979). 
6. Bock, G., Texturing Filament Yams in an Air Flow-Tangling Mechanism, Inter. Textile Bull. Spinning, 4, 359-389 (1981).

7. Bock, G., and Luenenschloss, J., Duesenstroemung und Schlingenbildung beim aerodynamischen Texturieren, Chemiefasem/Textilind. 31/83, 202-204 and 380-384 (1981).

8. Bock, G., and Luenenschloss, J., An Analysis of the Mechanism of Air-jet Texturing, in "Textile Machinery: Investing for the Future," The Textile Institute, Manchester, England, 1982.

9. Bock. G., and Luenenschloss, J.Heat Treatment of Air- jet Textured Polyester Filament Yams. Chemiefasem/ Textilind. 33/85 (2). 103-106 and E12 (1983).

10. Du Pont. Technical Information Bulletin. X-32. May 1955.

11. Du Pont. Technical Information Bulletin. X-154. Characteristics of Taslan Textured Yams, October 1961.

12. Fischer. K. E. and Wilson, D. K., Air-jet Texturing: An Alternative to Spun Yarn Production, in "Textile Machinery: Investing for the Future," The Textile Institute, Manchester, England, 1982.

13. Heberlein Yarn Technical Centre, Description of Test Methods for Air-jet Textured Filament Yams, 61 10, 13/ 8/80.

14. Heberlein, information sheet, 9/1982.

15. Kollu, T., Structure and Properties of Air-jet Textured Yarns, Masters thesis, UMIST, Manchester, 1982.

16. Piller, B., Development Trends in the Production of Air- jet Texturised Filament Yarn with Spun Yam Characteristics, Melliand Textilber.Eng. Ed. 60/8 (2), 128-136 (1979).

17. Piller, B., Shrinking Behaviour of Air-texturised, Modified Filament Yams, Melliand Textilber. Eng. Ed. 61/ 9 (4 and 5) 522-526 and 649-655 (1980).

18. Piller, B., and Lesykova, E., Structure and Economical Aspects of Air-jet Textured Filament Yarns, Melliand Textilber. Eng. Ed. 63/11 (7), 485-493 (1982).

19. Sen, H., A Study of Air-jet Type Bulked Filament Yarn Process, doctoral thesis, Loughborough University of Technology, England, 1970.

20. Sivakumar, V. R., The Mechanism of Bulking of Air Textured Yams, doctoral thesis, UMIST, Manchester, 1982.

21. Wilson, D. K., The Production of Textured Yarns by Methods Other than the Falsetwist Technique, Textile Prag. 9 (3), 63 pp (1977).

22. Wray, G. R., The Construction of Air-textured Filament Yams, in "Bulk, Stretch, and Texture," The Textile Institute, Manchester, England, 1966, pp. 18-28.

23. Wray, G. R., "The Properties of Air-textured Continuous Filament Yarns, J. Textile Inst. 60 (3), 102-126 (1969).

24. Wray, G. R., and Acar, M., The Production and the Properties of Air-jet Textured Continuous Filament Yams, in "Proc. International Textile Symposium," Izmir, Turkey, 2-4 Nov. 1981, Ege University Press, Izmir, 1984.

25. Wray, G. R., and Entwistle, J. H., An Investigation of the Air-jet Bulking Process, J. Textile Inst. 59 (11), 122- 136 (1968).

26. Wray, G. R., and Entwistle, J. H., The Modification of a Taslan Jet to Operate Low Air Pressures, J. Textile Inst. 60 (10), 41 1-419 (1969). 